\title{
(2) OPEN ACCESS \\ Reporting of pneumothorax in association with vaping devices and electronic cigarettes
}

\author{
Dietmar H Borchert $(1),{ }^{1}$ Hagen Kelm, ${ }^{2}$ Meghan Morean, ${ }^{3}$ Andrea Tannapfel ${ }^{4}$
}

${ }^{1}$ Department of Thoracic Surgery, Brandenburg Medical School Theodor Fontane, Neuruppin, Germany ${ }^{2}$ Respiratory Medicine, Brandenburg Medical School Theodor Fontane, Neuruppin, Germany

${ }^{3}$ Psychiatry, Yale School of Medicine, New Haven, Connecticut, USA

${ }^{4}$ Pathology, Ruhr University Bochum, Bochum, Germany

\section{Correspondence to} Dr Dietmar H Borchert; dietmar.borchert@doctors. org.uk

Accepted 23 November 2021

Check for updates

(c) BMJ Publishing Group Limited 2021. Re-use permitted under CC BY-NC. No commercial re-use. See rights and permissions. Published by BMJ.

To cite: Borchert DH, Kelm H Morean $\mathrm{M}$, et al. BMJ Case Rep 2021;14:e247844. doi:10.1136/bcr-2021247844

\section{SUMMARY}

Vaping may lead to spontaneous pneumothorax, but there are few published reports on this phenomenon. We present a case of vaping-related pneumothorax and make recommendations for structured reporting of this emerging cause for pneumothorax. A normalweight 34-year-old male presented to our emergency department with dyspnoea and back pain increasing over 24 hours. Chest X-ray showed a large right-sided pneumothorax. Three years ago, he had quit smoking cigarettes and switched to vaping. CT scan revealed bullae, and the patient received apical lung resection. Histology revealed mild alveolitis. Vaping is an emerging cause of lung injury. This report demonstrates a potential association between vaping and pneumothorax. However, structured reporting and future research are needed to establish a definitive (or causal) relationship between vaping and pneumothorax.

\section{BACKGROUND}

Vaping devices (electronic cigarettes (e-cigarette)) have gained popularity in recent years. Increased marketing of these devices has been paralleled by reports of e-cigarette or Vaping Product UseAssociated Lung Injury (EVALI), ${ }^{1}$ life-threatening bronchiolitis (similar to bronchiolitis obliterans or 'popcorn lung'), ${ }^{2}$ persistent severe fixed airway obstruction $^{3}$ and asthma. ${ }^{4}$ The first regular publication of a case of a vaping-related primary spontaneous pneumothorax (PSP) was published online in September 2019 from Harvard Medical School. ${ }^{5}$ A case of vaping-related secondary spontaneous pneumothorax (SSP) that was experienced shortly after treatment for vaping-induced pneumonitis was reported in November 2019 from Corpus Christi Medical Center in Texas, USA. ${ }^{6}$ Before and after these two publications, several conference abstracts of cases of vaping-related pneumothorax have been published.

PSP is a well-known disorder in young otherwise healthy adults that is associated with numerous risk factors. These risk factors include being underweight, lean habitus, scuba diving, high altitude, flying, smoking and, more specifically, smoking cannabis.

Risk factors like being underweight or atmospheric pressure changes generally are accepted as contributing to or causing pneumothorax. However, it is still a matter of debate whether other factors such as smoking cannabis predispose individuals to or otherwise contribute to PSP. One reason for this continuing debate is missing information from case reports and case series. ${ }^{78}$
As this report is now the seventh regular publication about pneumothorax in association with vaping, it is worthwhile considering the information that should be included for such cases and for reviews.

In this study, we used the CARE checklist to report a case of a patient presenting with a pneumothorax associated with vaping without the patient ever consuming cannabis. As we expect further cases to be reported for pneumothorax in relation to vaping, we report our case together with recommendations for standardised reporting of this relationship. In the absence of standardised reporting, drawing a causal link between vaping and PSP will be difficult if not impossible. ${ }^{9} 10$

\section{CASE PRESENTATION}

In October 2019, a 34-four-year-old white male presented to his general practitioner with a 1-day history of back pain, shortness of breath, tightness in his chest, burning pain in his right chest, retrosternal pain and feeling dizzy. Symptoms started after minor exertion during the afternoon on the day before presentation.

\section{Medical history}

No specific health problems occurred during adolescence. His previous medical history was otherwise unremarkable apart from a few rib fractures on his right side sustained through a cycling accident 3 years ago. There was no family history of lung disease. As a trained nurse, the patient worked in outpatient palliative care and devoted his free time to strength training and competitive sports. Due to his occupation, he had regular health checks, all negative for infectious diseases. He had no recent sports trauma to his chest. Despite being an active and internationally successful athlete, he smoked 20 cigarettes per day from the age of 21 years to the age of 31 years. Three years ago, he quit smoking by switching to vaping nicotine. He never smoked or vaped cannabis. He reported a pattern of regular deep and slow inhalation with the vaping device throughout the day similar to smoking a pack of cigarettes.

\section{Clinical findings}

On physical examination, we saw an athletic male with normal body mass index (BMI 23.6, $184 \mathrm{~cm}$ body height and $80 \mathrm{~kg}$ body weight). There were no signs of chronic lung disease such as finger clubbing, chronic cough, wheezing or sputum production. Neurology examination was unremarkable. During the patient's initial visit to his general practitioner, 


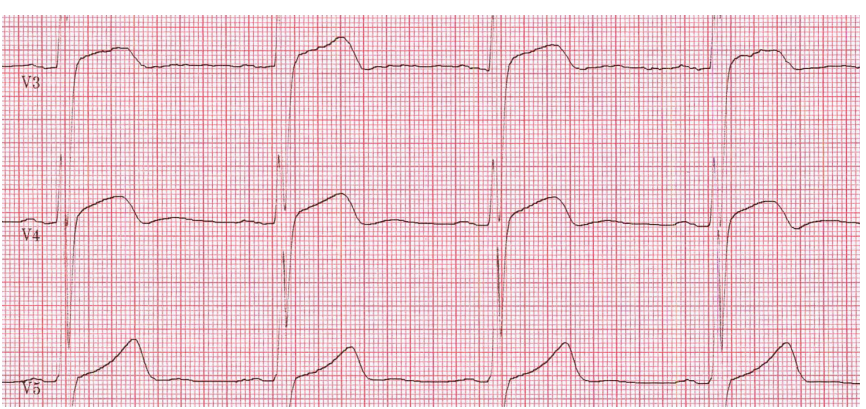

Figure 1 ECG on admission demonstrating ST-elevation in V3-V5 $(40 \mathrm{~Hz}, 50 \mathrm{~mm} / \mathrm{s}, 10 \mathrm{~mm} / \mathrm{mV})$.

vitals included a heart rate of 72 beats per minute, blood pressure of $143 / 91 \mathrm{~mm} \mathrm{Hg}$, peripheral oxygen saturation without air supply of $98 \%$ and a respiratory frequency of 15 per minute. His ECG demonstrated signs suggestive of myocarditis. The patient arrived at our emergency department 2 hours later with normal peripheral oxygen saturation of $98 \%$, but increasing tachypnoea with 24 breaths per minute. His heart rate and blood pressure remained normal, and there was no enlarged jugular vein pulse or cyanosis. Respiratory frequency returned to normal rates with $3 \mathrm{~L}$ of nasal air flow supply. ECG demonstrated again changes in V3-V5 suggestive of myocarditis (figure 1). His skin was dry and warm on palpation with a temperature of $36.8^{\circ} \mathrm{C}$, and his tongue was of healthy appearance. His heart sounds were regular on auscultation and breathing sounds were absent on the right side of his chest. Percussion revealed tympanitic chest sounds on the right. The patient complained of acute pain in his chest.

\section{Diagnostic assessment and therapeutic intervention}

His chest X-ray demonstrated a large (according to Collins formula ${ }^{11}$ ) right-sided pneumothorax (figure 2) and a small right-sided pleural effusion. Immediate insertion of a right-sided chest tube led to pain relief and normalisation of the ECG.

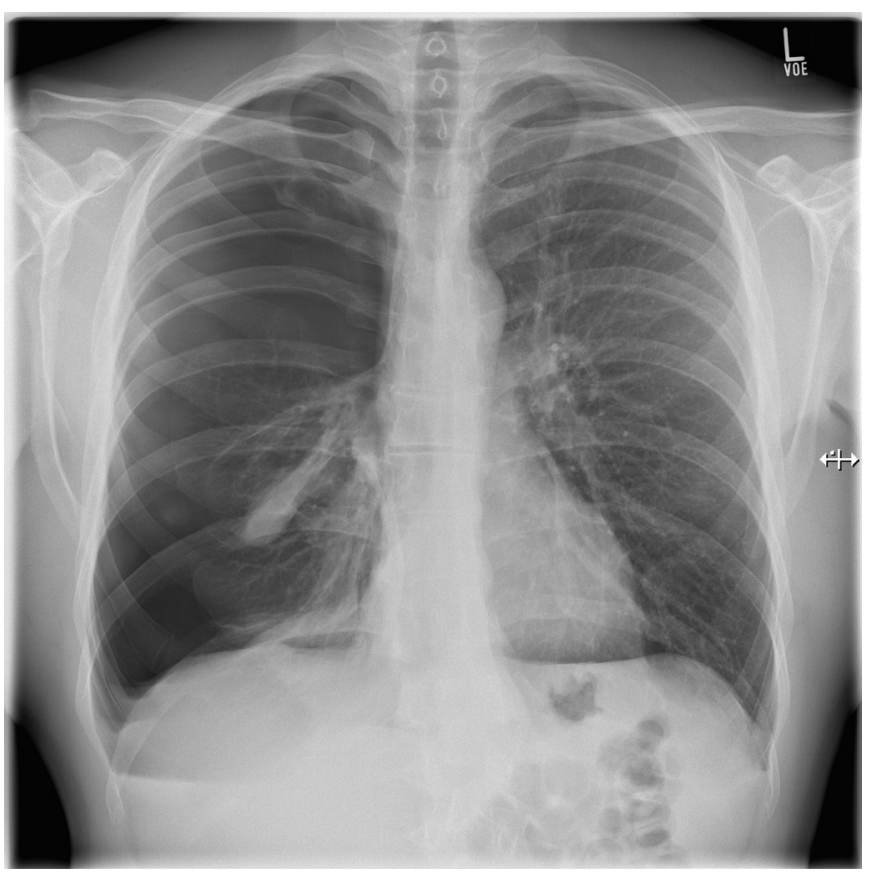

Figure 2 Posteroanterior chest X-ray in inspiration on presentation, demonstrating a large right-sided pneumothorax.
Diagnostic and therapeutic approaches were discussed with the patient, and a decision was made for a CT thorax scan. The CT scan demonstrated a bilateral inflated lung, the inserted chest tube on the right side, apical bleps of approximately $0.5-1.0 \mathrm{~cm}$ in diameter and a small stripe of remaining apical pneumothorax. Blood tests did not reveal any inflammation or other abnormal findings. After successful removal of the chest tube, the patient was discharged and returned for follow-up examination 1 week later in our outpatient department. During the visit, the patient stated his desire to proceed with bullae resection. Being active in martial arts and internationally successful, he feared of another episode of a pneumothorax leading to a further delay in his training.

The patient underwent video-assisted thoracoscopic surgery (VATS) resection of the apical bullae and partial apical pleurectomy. Intraoperatively, the apical bullae and a minor clear fluid collection could be demonstrated with no other visible lung pathology. The resection specimen revealed the site of ruptured bullae. The patient made an uneventful recovery. Perioperatively, the patient received routine tyloxapol inhalations four times daily. Standard analgesia contained oral metamizole, ibuprofen and oxycodone/naloxone.

\section{OUTCOME AND FOLLOW-UP}

After uneventful recovery and chest tube removal, the patient was discharged and re-evaluated 10 days later in the outpatient clinic. The patient reported normal breathing and no need for analgesia. He returned to work 4 weeks after discharge from our care and gradually resumed sports activities 6 weeks after surgery. The patient did not stop using his vaping device during treatment and continued use at follow-up. We invited the patient to review his histology slides under a twin microscope and counselled him regarding chronic health effects of smoking and vaping. He was asked to self-assess his vaping habits with the Self-Report Habit Index (SRHI, German version). While he reported being a frequent vaper, his SRHI score $(0.83)$ suggested only a modest level of habitual use.

\section{Histology}

The histology of this resection specimen revealed a subpleural bulla with typical histopathology of a pneumothorax with bulla rupture and small resorbed micro-bleeding. The surrounding lung tissue was characterised by a loss of lung parenchyma and by destruction of alveoli so that there was permanent dilation of airspaces. Large dilated airspaces-bulging from beneath the pleura-were clearly visible. There was also residual lung tissue with mild macrophagocytic alveolitis and signs of mild, chronic, fibrosing inflammation. Hyperdistention of alveolar ducts associated with rupture of alveolar septa was also seen. The specimen did not reveal lipid-laden macrophages.

\section{Vaping device used}

The basic anatomy of vaping devices can be found in vapingrelated internet content. ${ }^{12}$ Our patient used an atomiser-type Vapefly Brunhilde MTL RTA 8 mL (MTL-mouth to lung, RTArebuildable tank atomiser). The coil used was a Geek Vape Stainless Steel 316L, 15 wraps with $1.08 \Omega$, used with 20 W. Wicking for the coil was Wic ' $N$ ' Vape Cotton Bacon Prime. The Mod (battery carrier) was a VooPoo Drag 2 Box Mod. The vaping device was used with the following e-liquid: Dampfplanet Liquidbase VG50/PG50 (VG-vegetable glycerin, PG-propylene glycol) with Dampfplanet nicotine shot $20 \mathrm{mg} / \mathrm{mL}$ without flavour. The e-liquid was mixed with nicotine to achieve a concentration of 
$6 \mathrm{mg} / \mathrm{mL}$. The patient stated that he uses his vaping device on a daily basis and consumes approximately $16 \mathrm{~mL}$ of e-liquid per day.

\section{Analysis of previous case reports and recommendations for reporting}

We analysed six previously published case reports and case series $^{5 \text { 6 13-16 and several conference abstracts }}{ }^{17-25}$ of pneumothorax in association with vaping. We only analysed reports in English. Information on patient demographics, medical conditions, presenting symptoms, diagnostic findings and outcomes was examined. Results are reported in table 1 . Given the relative paucity of data on the relationship between vaping and pneumothorax, we used a tabular evaluation of existing case reports and conference papers. This method has been previously used by DeVito et al. ${ }^{26}$ In their review, the authors aimed to elucidate the impact of nicotine exposure from vaping devices on addiction and psychiatric symptoms and produced a qualitative table to depict standardised information. Here, we present a similar qualitative table that provides standardised information relevant to the aims of the current case report.

\section{DISCUSSION}

We presented a case of a young, healthy athlete who reported daily nicotine vaping and experienced an episode of spontaneous pneumothorax. This pneumothorax likely was a secondary spontaneous pneumothorax based on the presence of emphysematous bullae observed via his CT scan and histology slides. By analysing previous pneumothorax cases with vaping-related lung injury, we found two distinct types of pneumothorax presentation. Sixty per cent of reports analysed through table 1 demonstrated pneumothorax together with the truly horrifying changes of the lung parenchyma on CT scans that marked the EVALI outbreak in the USA with ground glass opacities (GGO), 'crazy paving patterns', absurdly large bullae in young people, bronchiectasis and volume loss (ie, the GGO group). ${ }^{27}$ In contrast, our patient was an athlete presenting with pneumothorax secondary to emphysema due to smoking and vaping nicotine without major structural changes of the lung parenchyma. The last seven cases in table 1 share similar clinical presentation and outcome including our case (ie, the non-GGO group). Chest X-rays and CT thorax scans of these patients did not show any major parenchymal changes together with a pneumothorax. There was no statistically significant age difference between the GGO and the non-GGO groups (27.1 vs 21.4 years, $\mathrm{p}=0.16$ ). BMI, nutritional status or body habitus of the patients rarely were reported, so we could not examine differences based on these factors. All patients in the non-GGO group were male, their previous medical history was unremarkable and they had no current infection or infectious diseases. Interestingly, although information on vaping duration was not included in seven cases reports, the numbers extracted give the impression that the duration of vaping in the GGO group was rather short compared with the more uncomplicated pneumothorax in the non-GGO group (10.8 vs 21.8 months, $\mathrm{p}=0.31$ ). The relatively short vaping duration observed in the GGO group is consistent with the presentation of EVALI cases observed during the 2019 outbreak in the USA.

Despite pneumothorax being a major complication of vaping and despite a strong association between smoking cannabis and pneumothorax as well as between vaping and use of cannabis in vaping products, information on cannabis use and toxicology proof was not available for all cases reviewed. In addition, information used to classify pneumothorax (PSP or SSP) like the presence of coughing or thoracic strain was not provided in several reports. Therefore, we reclassified the pneumothoraces into PSP and SSP according to an accepted definition and according to the information given in the reports. ${ }^{28}$ Only two of the pneumothoraces in the non-GGO group might be regarded as vaping-related primary spontaneous pneumothoraces. Interestingly, none of the patients in the non-GGO group developed bilateral pneumothorax, whereas 5 of 11 patients in the GGO group developed bilateral pneumothorax. In 7 of 11 cases in the GGO group, pneumothorax developed with a latency of 4-18 days after presentation. Furthermore, 4 of 11 patients in the GGO-pneumothorax group needed ECMO support. None of the patients similar to our patient (non-GGO group) developed respiratory failure. In both groups, recurrent pneumothoraces and bronchial fistula occurred. Interestingly, Gonsalves and colleagues reported recurrent pneumothorax after PSP in three out of three EVALI cases. ${ }^{29}$ Here, we found recurrent pneumothorax after PSP and after SSP in both the GGO and non-GGO groups. In five of the cases reviewed in table 1, no information on pneumothorax management could be retrieved.

Table 2 is a checklist-type table that we created based on previous reviews of EVALI cases and our own experience that may be used to encourage standardised reporting of vapingrelated pneumothorax. ${ }^{29-33}$

Our patient also presented with rather rare ECG changes suggestive of myocarditis. There are few reports of such ECG changes with a right-sided pneumothorax. ${ }^{34}$ ECG changes resolved quickly after chest tube insertion on the day of admission. Management with VATS resection of the right lung apex was successful, and the patient restarted training in martial arts 6 weeks after the operation. Histology of the lung specimen revealed typical pathology of nicotine smoking-related pneumothorax. No specific investigations are known for pathology specimens from vaping-associated pneumothorax.

The patient demonstrated in-depth knowledge of his vaping device and reported that it helped him to quit smoking 3 years ago. Prior to switching to vaping, the patient smoked approximately 20 cigarettes per day for a period of 10 years despite being a successful athlete. The patient reported his athletic ability increased after switching to vaping. The patient was well aware that, in the long term, there might be significant changes to his fitness due to structural changes in his lungs and vessels. The patient clearly understood that vaping nicotine might help quit smoking nicotine but might not lead to a decreased spectrum of related illnesses.

As was the case with smoking, it likely will be decades after the introduction of e-cigarettes until the full picture regarding associations between vaping and diseases emerges. The current report is only the seventh case report to highlight vaping-related pneumothorax. However, pneumothorax in young adults has been strongly associated with cigarette smoking and cannabis use; case-control studies have established both as significant risk factors for pneumothorax. ${ }^{35}$ Yet, evidence of a causal relationship is lacking. Moreover, whole case series of vaping-related lung injury have been published without any patient experiencing a pneumothorax. ${ }^{32} 36$ Compared with this report, Jonas et al identified 8 patients with pneumothorax among 216 published cases with vaping-associated lung injury. ${ }^{31}$ In 2019 , research has, for the first time, tried to identify cannabinoids in lung tissue of young adults with pneumothorax. ${ }^{7}$ While this is an important step in understanding the relationship between cannabis use and pneumothorax, evidence of cannabinoids in lung tissue does not provide proof of a pathology mechanism. Similarly, it might be difficult to establish a causal relationship between vaping 


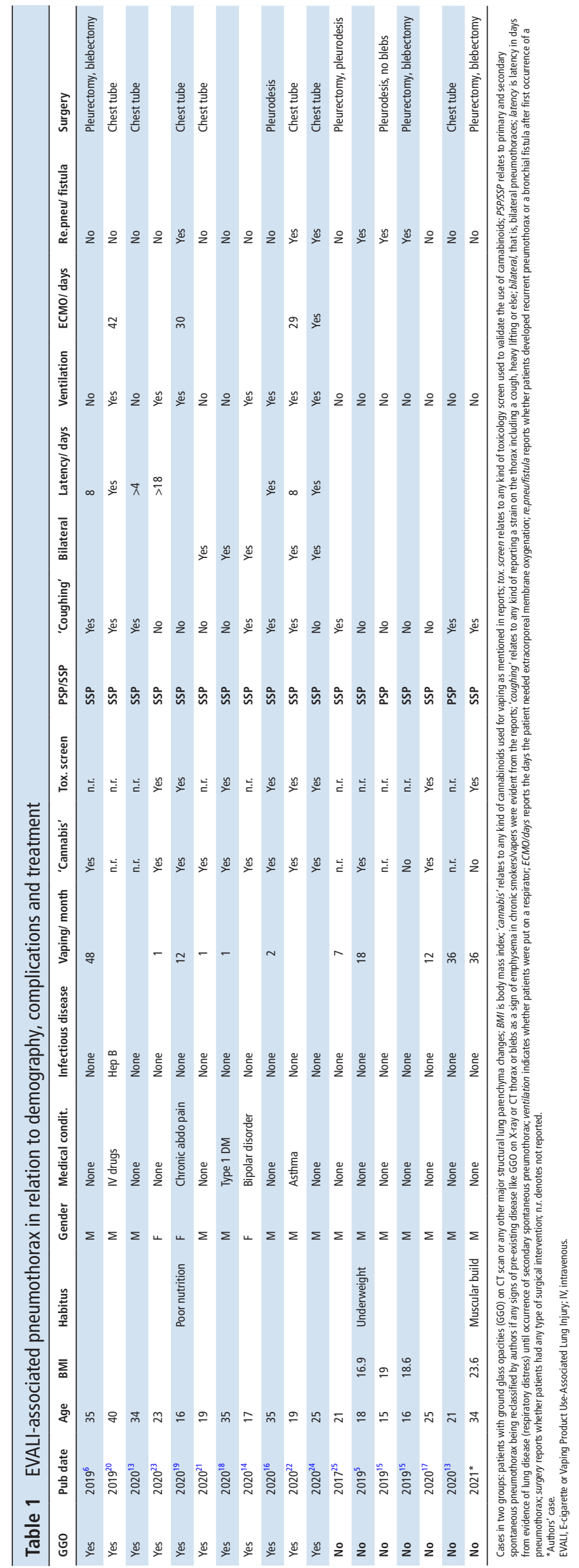




\begin{tabular}{|c|c|}
\hline Demography & Symptoms \\
\hline Sex & Pulmonary \\
\hline Age & Gastrointestinal \\
\hline Race & General \\
\hline Country & Cough \\
\hline Body habitus & Dyspnoea \\
\hline BMI & Hemoptysis \\
\hline Lung disease & Pleuritic chest pain \\
\hline Medical conditions & Type of pain \\
\hline Infectious disease & Sweats, fever, chills \\
\hline \multirow[t]{2}{*}{ Familiy history of lung disease } & Strain on thorax \\
\hline & Heavy lifting \\
\hline \multicolumn{2}{|l|}{ Technical } \\
\hline \multicolumn{2}{|l|}{ Substances used, for example, cannabis } \\
\hline Nicotine and cannabis serum concentrations, urine toxicology & Radiology \\
\hline E-cigarette/vaping device & Lung injury pattern \\
\hline Device name & CT thorax scan \\
\hline $\begin{array}{l}\text { Device setting (tank size, filling, flavouring, reusable etc., any technical } \\
\text { information) }\end{array}$ & Chest X-ray \\
\hline \multicolumn{2}{|l|}{ Propylen glycol/vegetable glycerin ratio of e-liquid used } \\
\hline Nicotine concentration, mg/mL & Pathology \\
\hline Atomiser, cartomiser, clearomiser & Cytology \\
\hline Electronic settings of device & Histology† \\
\hline Preferred coil resistance/ $\Omega$ & Blood results \\
\hline Referred heating power/W & Immunology results \\
\hline Coil material & Lung function tests \\
\hline \multicolumn{2}{|l|}{ Patient perceived power output level safe/hot/extremly hot } \\
\hline Conventional smoking & Intervention \\
\hline Smoking e-cigarette/vaping & HF nasal canula \\
\hline Smoking and vaping/dual user & $\begin{array}{l}\text { Mechanical } \\
\text { ventilation }\end{array}$ \\
\hline Pack years conventional cigarette & ECMO \\
\hline Joint years* & Bronchoscopy \\
\hline Duration of e-cigarette or vaping/years & Bronchial lavage \\
\hline Inhalation habits (eg, dripping; MTL, DTL) & Corticosteroids \\
\hline Puff volume/mL & Transbro. biopsy \\
\hline Puff duration/s & Open lung biopsy \\
\hline Frequency of daily use & Level of care \\
\hline Measure of vaping patterns with research device & Chest tube \\
\hline \multirow[t]{2}{*}{ Measuring air flow rate with vaping device } & VATS \\
\hline & Thoracotomy \\
\hline Psychometric testing & Days on ICU \\
\hline \multirow[t]{2}{*}{ dSRH $\neq$, EMCDDA questionnaire } & Days on ventilator \\
\hline & Days on ECMO \\
\hline Follow-up & Final diagnosis \\
\hline \multicolumn{2}{|l|}{ Recurrent pneumothorax } \\
\hline Effect of counselling & \\
\hline
\end{tabular}

Items reported by review authors.

*Joint-year exposure (equivalent to one joint per day for 1 year), MTL-mouth to lung, DTL—direct to lung, Dripping — a vaping technique where e-liquid is directly dripped onto the coil to produce vapour, instead of the e-liquid coming from the e-liquid tank (needs experience of vaper). ${ }^{42}$

tConsider searching for lipid-laden macrophages and red oil 0 staining in histology similar to pathology reports from EVALI cases.

‡dSRHI, Self-Reported Habit Index using a validated German version; ${ }^{41} 43$ EMCDDA, European

Monitoring Centre for Drugs and Drug Addiction. Measurement of vaping patterns and air flow

rate can be realised using the CReSS pocket device from Borgwaldt Körber Solutions Hamburg

(clinical research support system). This is a portable and autonomous battery-operated device that

automatically measures smoking behaviour parameters or characteristics including date, time, start and

end of smoking, puffs per cigarette, puff volume and puff duration.

$\mathrm{BMI}$, body mass index; EVALI, E-cigarette or Vaping Product Use-Associated Lung Injury; HF, high flow;

ICU, intensive care unit; VATS, video-assisted thoracoscopic surgery.

and pneumothorax. However, if such a relationship exists, we expect to see a rise in cases of pneumothorax that accompanies the increased popularity of vaping. Building on the evidence of a cannabis-pneumothorax association, we provided recommendations through table 2 about reporting vaping-associated pneumothorax. As no systematic pathology examination of lung tissue from patients with vaping-associated pneumothorax exists today, there should be an international agreement on what to look for in such specimens.

The mechanism of developing a pneumothorax with vaping is likely to be complex. A factor that has long been suspected of contributing to pneumothorax is inhalation technique. Of note, inhalation technique is one of the main differences between smoking tobacco cigarettes, smoking cannabis and vaping. The importance of researching variation in inhalation technique is underscored by the results of a study on 'dripping and e-cigarettes' from Yale University School of Medicine. ${ }^{37}$ Dr Krishnan-Sarin and colleagues describe that, among 1080 (main sample $\mathrm{n}=7045$ ) students from eight Connecticut high schools, 282 students (mean age, 16.4 years) used dripping. Dripping is a technique where e-liquids are vaporised directly via application to the atomiser coil to produce a stronger flavour, thicker cloud of vapour and a 'stronger throat hit'. Dripping can lead to inhalation of higher temperature vapour and exposure to non-nicotinic toxic byproducts such as volatile aldehydes (formaldehyde) in toxic concentrations. Therefore, it is strongly recommended to ask patients about inhalation technique to understand the development of vaping-associated pneumothorax.

A major criticism in reporting of cannabis-related and smoking-related pneumothorax has been the absence of standardised information about smoking habits in case reports and cohort studies. ${ }^{31} 323839$ Recognising similar problems in addiction research, the European Centre for Drugs and Drug Addiction (EMCDDA) recommended the use of standard questionnaires in 2002. ${ }^{40}$ The EMCDDA questionnaire has been used in a large Danish cohort study to establish cannabis as a risk factor for PSP, ${ }^{35}$ but the EMCDDA questionnaire has not yet been updated to include assessments of e-cigarette use. Until psychometrically sound measures of e-cigarette use are included in large, standardised surveys like the EMCDDA, it is critical to source reliable and valid measures of e-cigarette use and related behaviours elsewhere. In this study, we used the SRHI, a recently validated measure of habitual e-cigarette use. ${ }^{41}$ To increase the scientific rigour and interpretability of findings related to e-cigarette use, the use of validated measures like the SRHI is strongly recommended.

Contributors DHB provided surgical service to the patient reported here, HK provided respiratory medicine support and counselling services to the patient and supervised reporting of the case, MM first advised on psychometric testing of the patient and than co-wrote and corrected the case report including discussion of requirements from the reviewers and AT performed extensive testing of the lung specimen resected. AT was involved as a champion in lung pathology and advised on writing of the report.

Funding The authors have not declared a specific grant for this research from any funding agency in the public, commercial or not-for-profit sectors.

Competing interests None declared.

Patient consent for publication Consent obtained directly from patient(s).

Provenance and peer review Not commissioned; externally peer reviewed.

Open access This is an open access article distributed in accordance with the Creative Commons Attribution Non Commercial (CC BY-NC 4.0) license, which permits others to distribute, remix, adapt, build upon this work non-commercially, and license their derivative works on different terms, provided the original work is properly cited and the use is non-commercial. See: http://creativecommons.org/ licenses/by-nc/4.01.

Case reports provide a valuable learning resource for the scientific community and can indicate areas of interest for future research. They should not be used in isolation to guide treatment choices or public health policy. 


\section{Patient's perspective}

People are likely to think about lifestyle factors contributing to a dramatic episode of illness and hospitalisation while recovering. After reading a lot and asking myself questions, it is still difficult for me to decide whether there is an association between my vaping and experiencing an episode of recurrent pneumothorax. If there is, how are we going to find out the most important contributing factors? There are a wide variety of flavours, mixing ratios of VG and PG and nicotine concentrations in the e-liquid. Moreover, there are different metals used for the coils, energy settings and inhalation techniques. These multiple factors might render it impossible to estimate any correlation between vaping and pneumothorax. Generally, I am very grateful for having my vaping devices as it helped me quit smoking. Currently in my opinion, smoking is still much more harmful than vaping. Taking my occupation as a palliative care nurse into account, this episode with a pneumothorax sharpened my existing views of risks of daily life. One should live the life he wants to live and should enjoy what he wants to enjoy. To know about risks is absolutely worthwhile for making informed decisions, but quality of life is very individual and important too.

\section{Learning points}

- Vaping nicotine may cause pneumothorax.

- For patients with pneumothorax and a background of vaping, ask about inhalation technique and e-liquids used.

- Ask for vaping habits using, for example, the Self-Habit Reporting Index.

- Counsel for vaping-related health effects.

\section{ORCID iD}

Dietmar H Borchert http://orcid.org/0000-0002-6050-6324

\section{REFERENCES}

1 Navon L, Jones CM, Ghinai I, et al. Risk Factors for E-Cigarette, or Vaping, Product Use-Associated Lung Injury (EVALI) Among Adults Who Use E-Cigarette, or Vaping, Products - Illinois, July-October 2019. MMWR Morb Mortal Wkly Rep 2019;68:1034-9.

2 Landman ST, Dhaliwal I, Mackenzie CA, et al. Life-threatening bronchiolitis related to electronic cigarette use in a Canadian youth. CMAJ 2019;191:E1321-31.

3 Macedonia TV, Krefft SD, Rose CS. Persistent severe fixed airways obstruction in a High-Dosing e-cigarette user. J Gen Intern Med 2020;35:345-9.

4 Clapp PW, Jaspers I. Electronic cigarettes: their constituents and potential links to asthma. Curr Allergy Asthma Rep 2017;17:79.

5 Bonilla A, Blair AJ, Alamro SM, et al. Recurrent spontaneous pneumothoraces and vaping in an 18-year-old man: a case report and review of the literature. J Med Case Rep 2019;13:283.

6 Sharma M, Anjum H, Bulathsinghala CP, et al. A case report of secondary spontaneous pneumothorax induced by Vape. Cureus 2019;11:e6067.

7 Bisconti M, Marulli G, Pacifici R, et al. Cannabinoids identification in lung tissues of young cannabis smokers operated for primary spontaneous pneumothorax and correlation with pathologic findings. Respiration 2019;98:503-11.

8 Underner M, Urban T, Perriot J, et al. [Spontaneous pneumothorax and lung emphysema in cannabis users]. Rev Pneumol Clin 2018;74:400-15.

9 Gagnier JJ, Kienle G, Altman DG, et al. The CARE guidelines: consensus-based clinical case reporting Guideline development. BMJ Case Rep 2013;2013. doi:10.1136/bcr2013-201554. [Epub ahead of print: 23 Oct 2013].

10 Riley DS, Barber MS, Kienle GS, et al. CARE guidelines for case reports: explanation and elaboration document. J Clin Epidemiol 2017;89:218-35.

11 Collins CD, Lopez A, Mathie A, et al. Quantification of pneumothorax size on chest radiographs using interpleural distances: regression analysis based on volume measurements from helical CT. AJR Am J Roentgenol 1995;165:1127-30.
12 Mishub. Tutorial: guide to selecting the right Vape device. 31-8-2015. 21-1-2020.

13 Ali M, Khan K, Buch M, et al. A case series of Vaping-Induced lung injury in a community hospital setting. Case Rep Pulmono/ 2020;2020:9631916.

14 Reddy A, Jenssen BP, Chidambaram A, et al. Characterizing e-cigarette vapingassociated lung injury in the pediatric intensive care unit. Pediatr Pulmonol 2021;56:162-70.

15 Skertich NJ, Sullivan GA, Madonna MB, et al. Vaping is a risk factor for spontaneous pneumothorax: two cases. Journal of Pediatric Surgery Case Reports 2019;50:101305.

16 Wu M, Mohammed T-LH. Electronic cigarette or Vaping product Use-associated lung injury: diffuse alveolar damage. Radiol Cardiothorac Imaging 2020;2:e200027.

17 Ali F, Taweesedt P. Combo of vaping, cannabis, and tobacco exposure: shorter time to bullous lung disease and pneumothorax. Chest 2020;158:A1617.

18 Corona EF, Patel L. Don't let vaping get under your skin. Chest 2020;158:A1609.

19 Dettori A, Afolabi F, Rao DR. Severe presentation of e-cigarette or Vaping product associated lung injury leading to ECMO and tracheostomy placement. Am J Respir Crit Care Med 2020;201:A6038.

20 Hackett D, Axelband J, Trager J, et al. 1099: it all started with VAPING. Crit Care Med 2020;48:529.

21 Hussain H, Sehring M, Taneja D. Smoke everywhere, from lungs to spine! Chest 2020;158:A950.

22 Kumar T, Kurz D, Fares E. Blowing bubbles: a case of Pneumatoceles due to Vaping. Am J Respir Crit Care Med 2020;201:A7038.

23 Maslonka M, Meredith WB, Norton D. The Vapes of Wrath: pneumothorax risk in THC Vaping associated lung injury. Am J Respir Crit Care Med 2020;201:A1841.

24 Mathew A, Krow S, Kaul M, et al. Lung entrapment in Vaping associated lung injury. Am J Respir Crit Care Med 2020;201:A7054.

25 Vaping TL. And tension pneumothorax: a life-threatening association. American Journal of Respiratory and Critical Care Medicine 2017;2017:A2052.

26 DeVito EE, Krishnan-Sarin S. E-Cigarettes: impact of E-Liquid components and device characteristics on nicotine exposure. Curr Neuropharmacol 2018;16:438-59.

27 Kligerman S, Raptis C, Larsen B, et al. Radiologic, pathologic, clinical, and physiologic findings of electronic cigarette or Vaping product Use-associated lung injury (EVALI): evolving knowledge and remaining questions. Radiology 2020;294:491-505.

28 Eggeling S. [Pneumothorax]. Zentralb/ Chir 2021;146:126-44.

29 Gonsalves CL, Zhu JW, Kam AJ. Diagnosis and acute management of e-cigarette or Vaping product Use-Associated lung injury in the pediatric population: a systematic review. J Pediatr 2021;228:260-70.

30 Hage R, Fretz V, Schuurmans MM. Electronic cigarettes and vaping associated pulmonary illness (VAPI): a narrative review. Pulmonology 2020;26:291-303.

31 Jonas AM, Raj R. Vaping-Related acute parenchymal lung injury: a systematic review. Chest 2020;158:1555-65.

32 MacMurdo M, Lin C, Saeedan MB, et al. E-Cigarette or Vaping product UseAssociated lung injury: clinical, radiologic, and pathologic findings of 15 cases. Chest 2020;157:e181-7

33 Tzortzi A, Kapetanstrataki M, Evangelopoulou V, et al. A systematic literature review of E-Cigarette-Related illness and injury: not just for the Respirologist. Int J Environ Res Public Health 2020;17. doi:10.3390/ijerph17072248. [Epub ahead of print: 2703 2020].

34 Alzghoul B, Innabi A, Shanbhag A, et al. latrogenic right-sided pneumothorax presenting as ST-segment elevation: a rare case report and review of literature. Case Rep Crit Care 2017;2017:1-3.

35 Hedevang Olesen W, Katballe N, Sindby JE, et al. Cannabis increased the risk of primary spontaneous pneumothorax in tobacco smokers: a case-control study. Eur J Cardiothorac Surg 2017;52:679-85.

36 Fryman C, Lou B, Weber AG, et al. Acute respiratory failure associated with Vaping. Chest 2020;157:e63-8.

37 Krishnan-Sarin S, Morean M, Kong G, et al. E-Cigarettes and 'Dripping' Among HighSchool Youth. Pediatrics 2017;139. doi:10.1542/peds.2016-3224. [Epub ahead of print: 0602 2017].

38 Hallowell RW, Feldman MB, Little BP, et al. Case 38-2019: a 20-year-old man with dyspnea and abnormalities on chest imaging. N Eng/ J Med 2019;381:2353-63.

39 Hua M, Talbot P. Potential health effects of electronic cigarettes: a systematic review of case reports. Prev Med Rep 2016;4:169-78

40 EMCDDA project CT.99.EP.08 B LEA2. Handbook for surveys on drug use among the general population - final report. 2002. European Monitoring Centre for Drugs and Drug Addiction (EMCDDA).

41 Morean ME, DeMartini KS, Foster D, et al. The self-report habit index: assessing habitual marijuana, alcohol, e-cigarette, and cigarette use. Drug Alcohol Depend 2018;186:207-14.

42 Talih S, Balhas Z, Salman R, et al. 'Direct Dripping': A High-Temperature, HighFormaldehyde Emission Electronic Cigarette Use Method. Nicotine Tob Res 2016;18:453-9.

43 Thurn J. (In)aktiv aus Gewohnheit? - Theoretische und empirische Fundierung des Konstrukts Gewohnheit und Validierung des deutschsprachigen Self Report Habit Index (dSRHI) für körperliche Aktivität. 2014. 28-1-2020. 
Copyright 2021 BMJ Publishing Group. All rights reserved. For permission to reuse any of this content visit https://www.bmj.com/company/products-services/rights-and-licensing/permissions/

BMJ Case Report Fellows may re-use this article for personal use and teaching without any further permission.

Become a Fellow of BMJ Case Reports today and you can:

- Submit as many cases as you like

Enjoy fast sympathetic peer review and rapid publication of accepted articles

Access all the published articles

Re-use any of the published material for personal use and teaching without further permission

Customer Service

If you have any further queries about your subscription, please contact our customer services team on +44 (0) 2071111105 or via email at support@bmj.com.

Visit casereports.bmj.com for more articles like this and to become a Fellow 